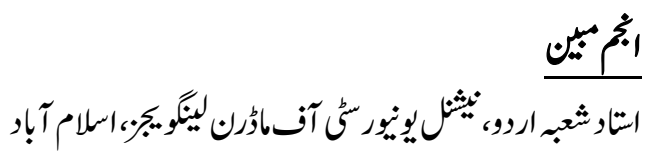

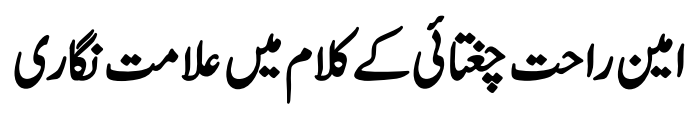

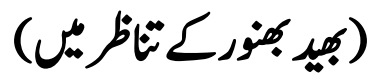

Anjum Mobeen

Lecturer, Department of Urdu, NUML, Islamabad.

\title{
Symbolism in Amin Rahat Chughtai's Poetry with Particular Reference to His Work Bhid Bhanwar
}

Amin Rahat Chughtai holds a special position as a researcher, critic poet particularly of Naat and Hikko. Bhid Bhanwar is his collection of poems and ghazals published in 1984. His poems and ghazals has similar tone and style. On one hand his poems fulfil the criteria of modern poem and on the other hand his poem is rooted in the tradion. He follows a particular system of symbols in his poetry. This system is based in four main symbols forest, alley or street, fire and mirror. Beside there is a variety of topics in his poetry. His poetry deals with feelings, love, affection, excitement, self realization relationship with the tradition of past, problems of urban life, indifference of politicians. These are the issues every refined reader would like to read.

Key Words: Amin Rahat Chughtai, Researcher, Critic, Naat, Hikko, Ghid Bhanwar, Poems, Ghazals.

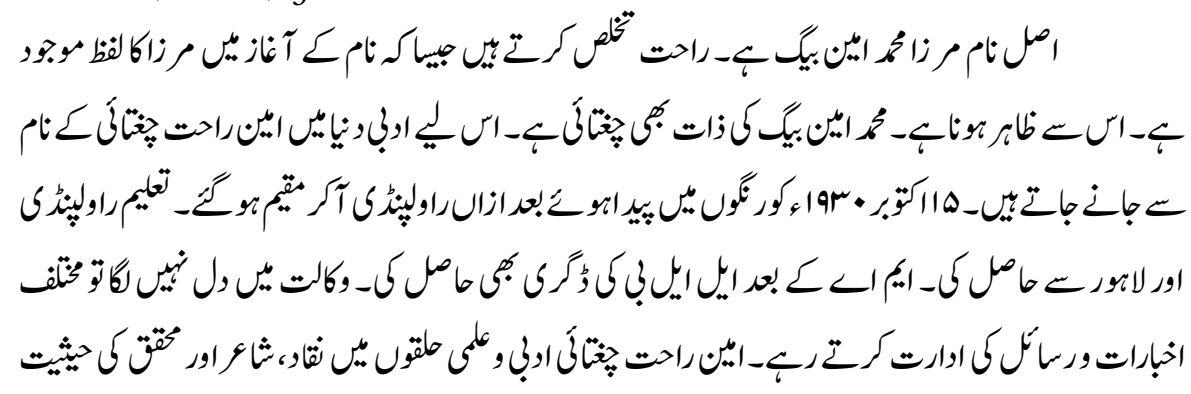




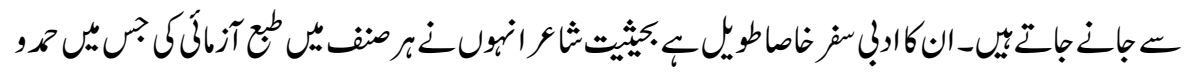

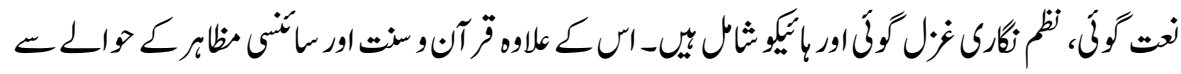

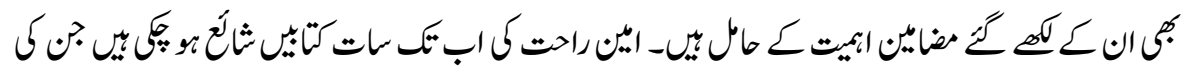
تهيل ليوب:

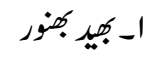

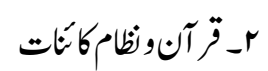

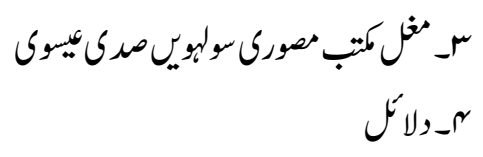

$$
\text { 4ــإمانيث }
$$

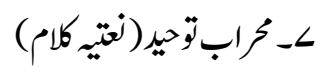

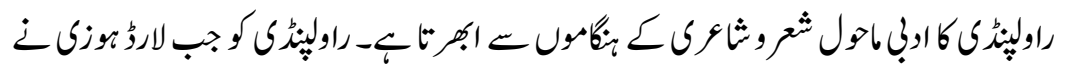

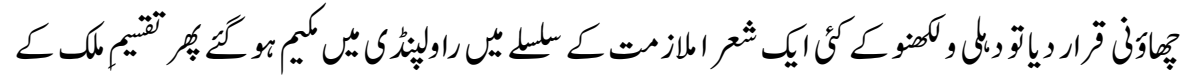

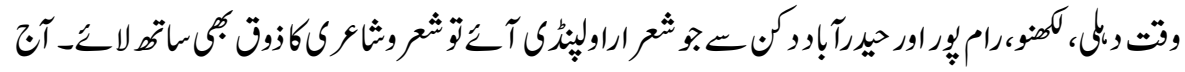

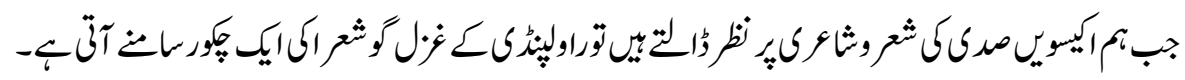

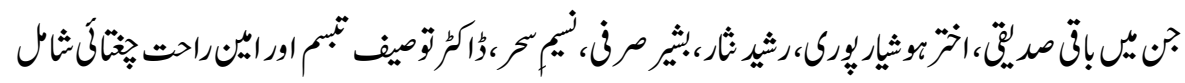

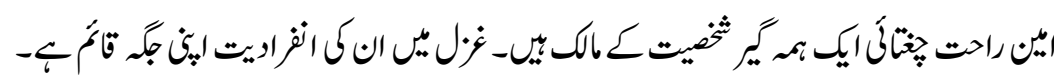

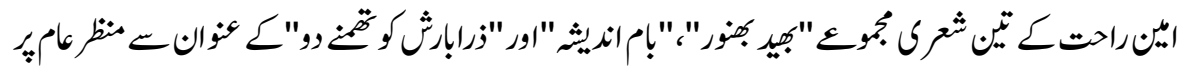

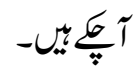

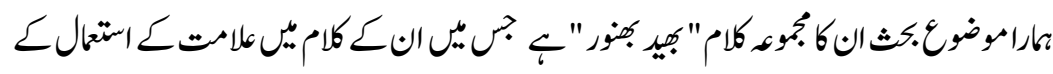

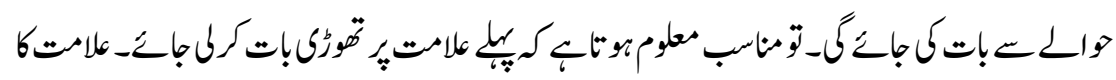




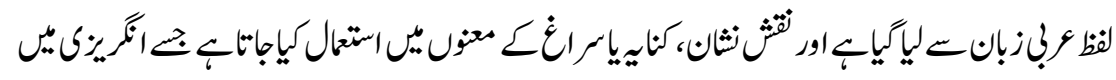
Symbol

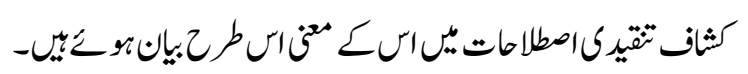

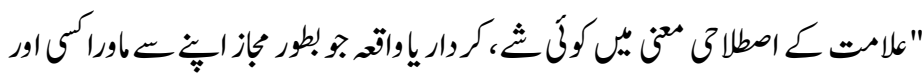

$$
\text { (1) }
$$

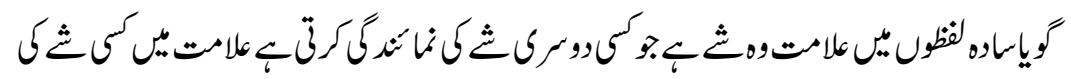

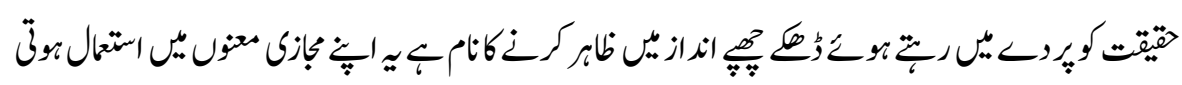

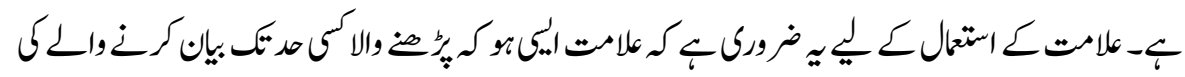

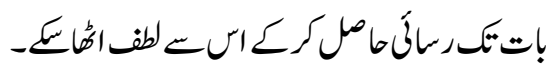

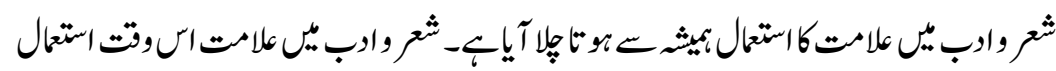

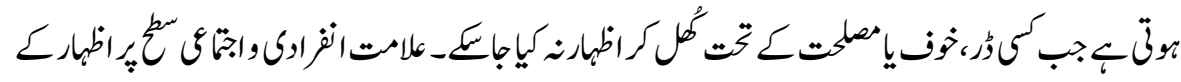

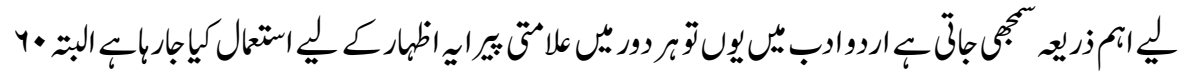

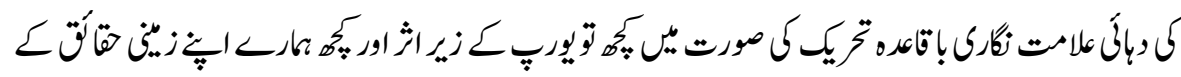

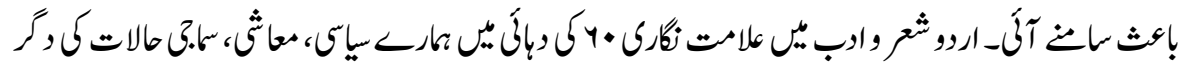

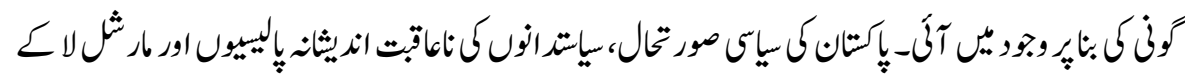

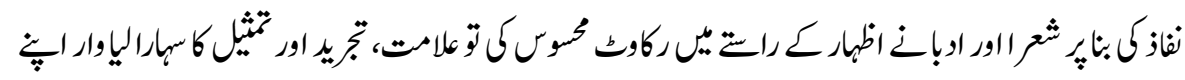

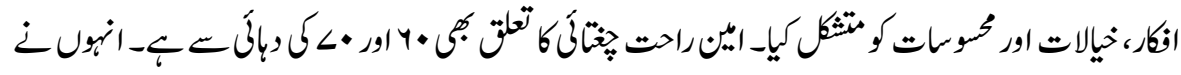

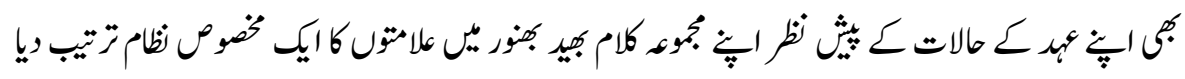

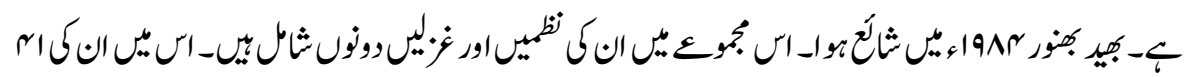

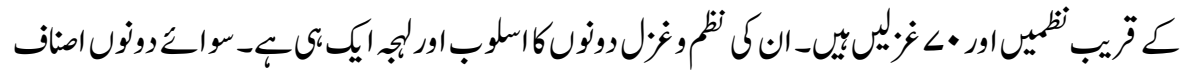

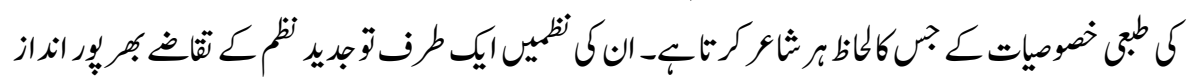

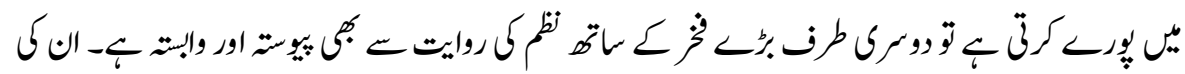




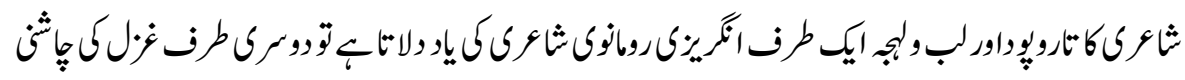

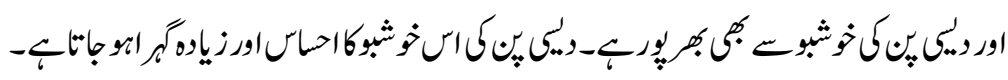

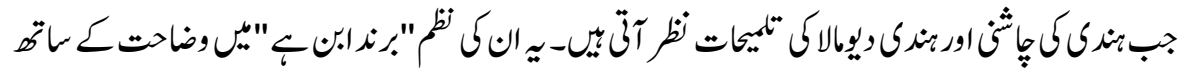

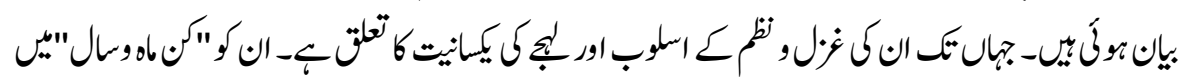
:

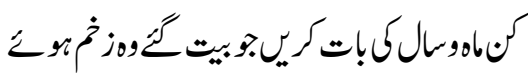

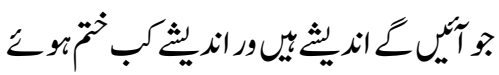

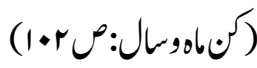

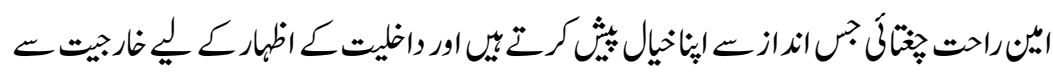

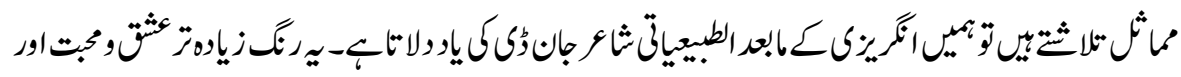

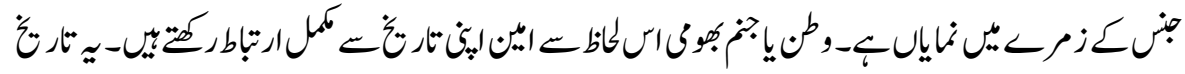

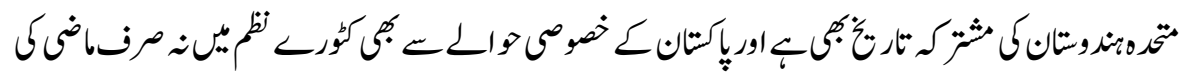

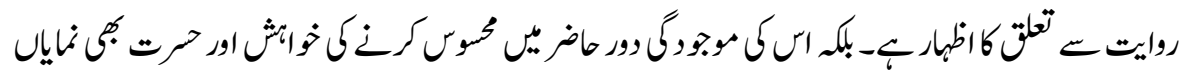

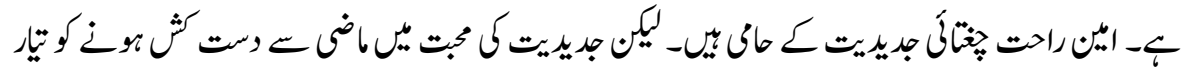

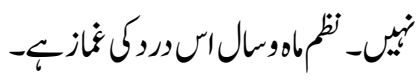

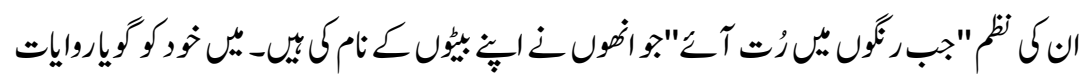

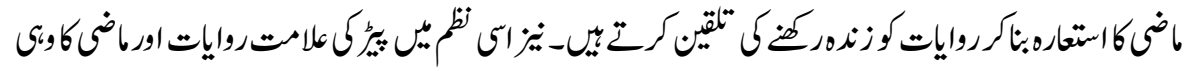

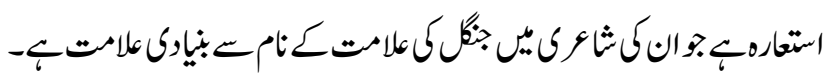

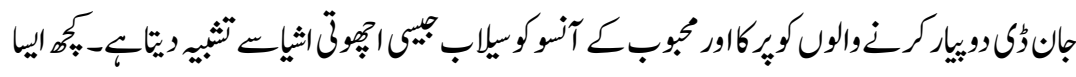

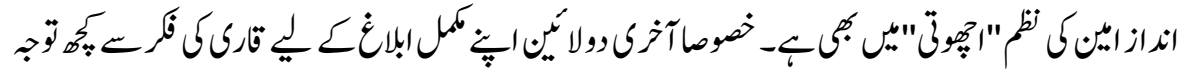

$$
\text { بات اكرى، }
$$

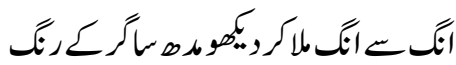




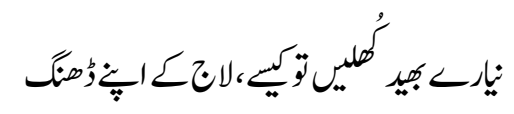

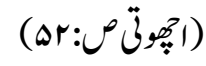

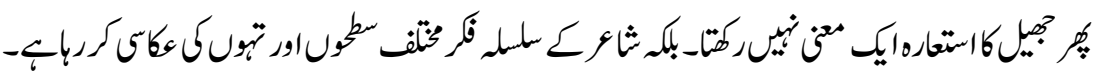

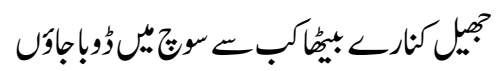

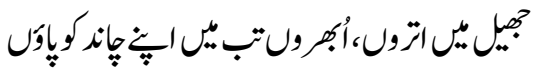

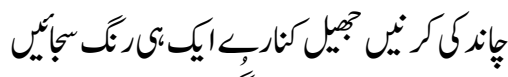

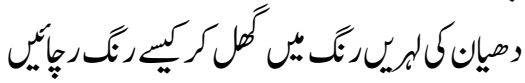

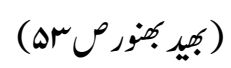

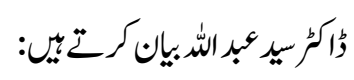

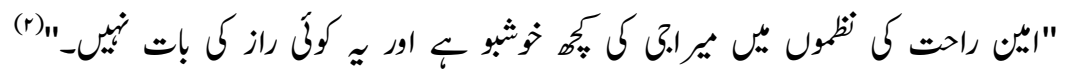

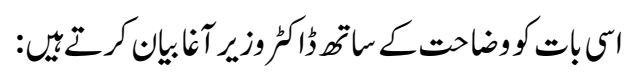

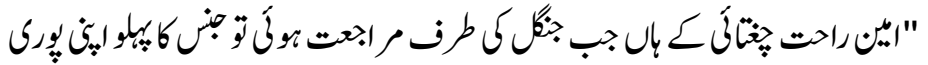

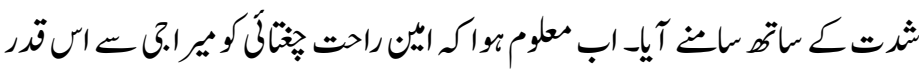

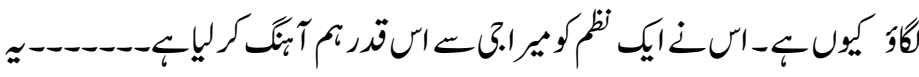

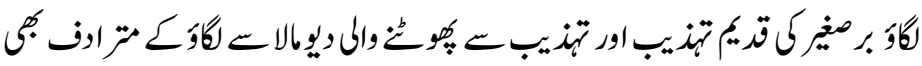

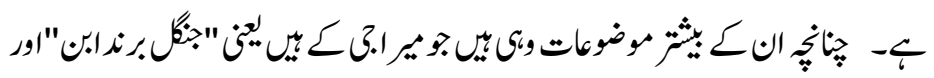

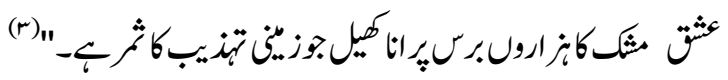

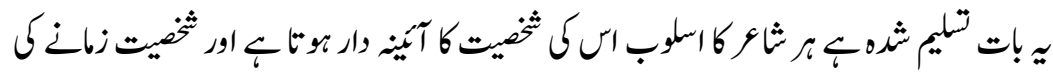

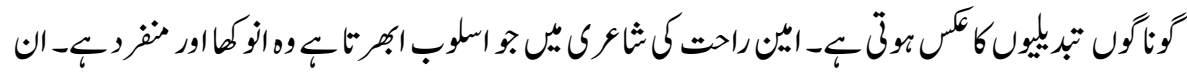

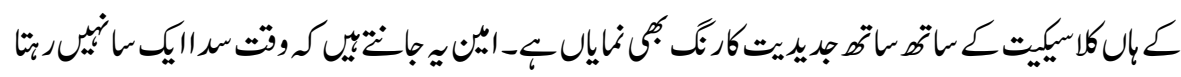

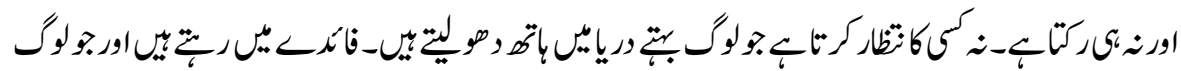

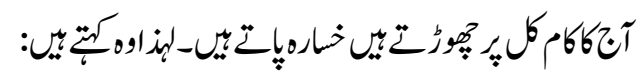




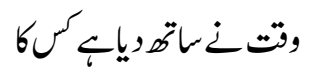

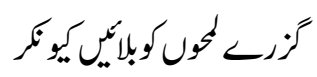

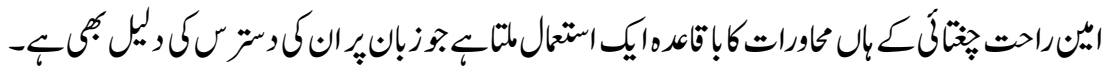

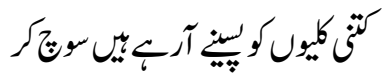

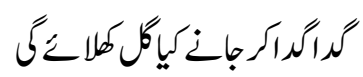

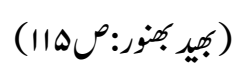

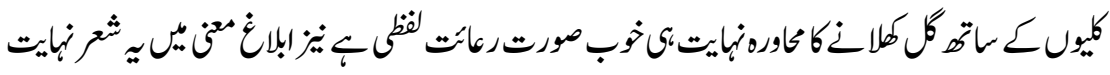

$$
\begin{aligned}
& \text { وكوكَّات تغيانت }
\end{aligned}
$$

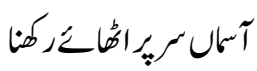

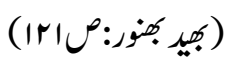

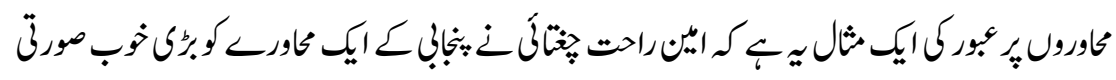

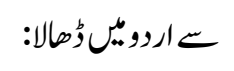

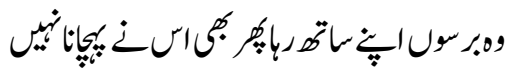

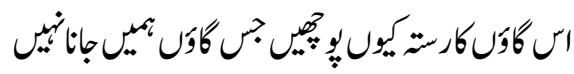

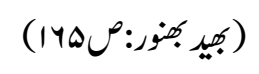

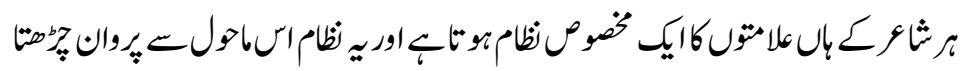

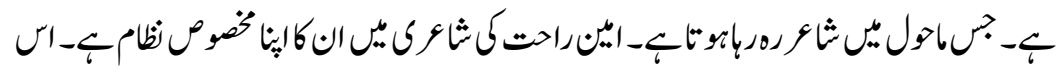

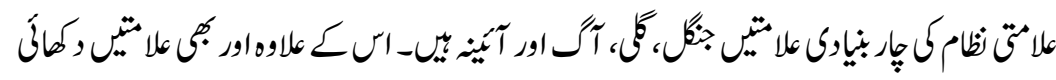

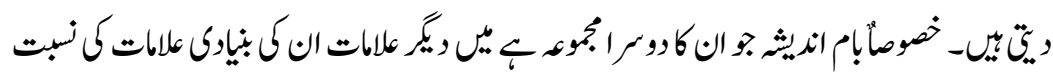

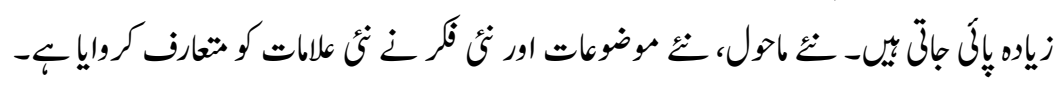

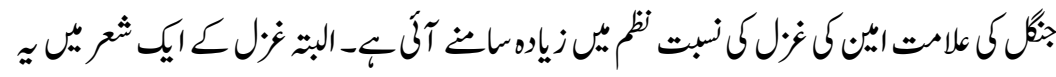

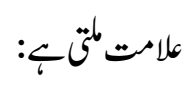




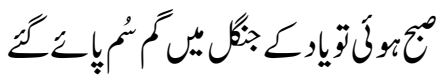

$$
\begin{aligned}
& \text {. }
\end{aligned}
$$

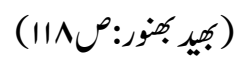

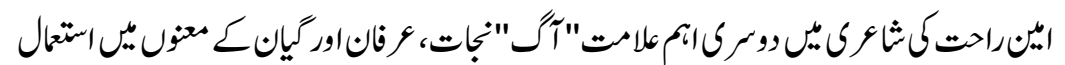

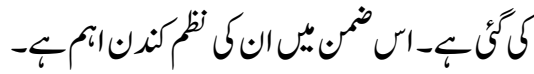

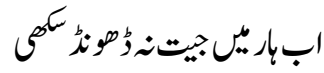

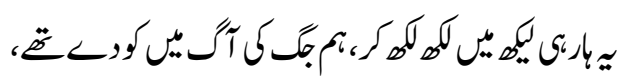

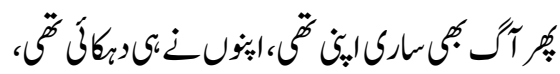

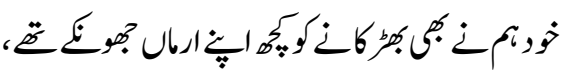

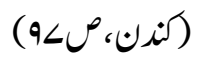

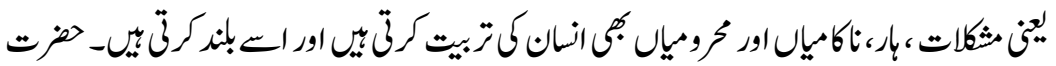

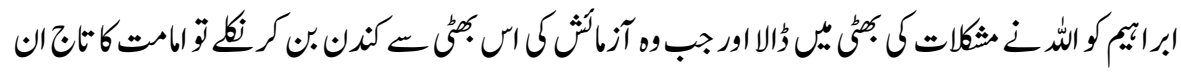

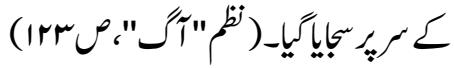

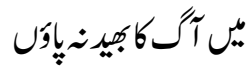

$$
\begin{aligned}
& \text { تن ثنكسمه بمراول }
\end{aligned}
$$

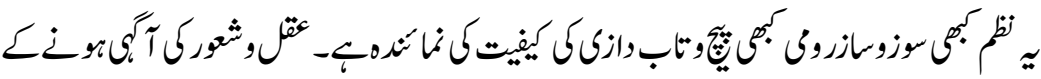

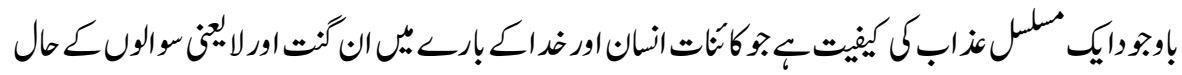

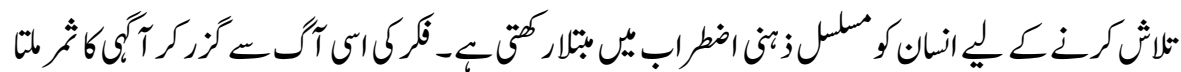

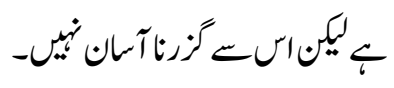

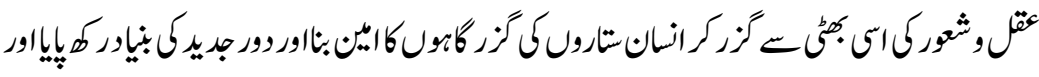

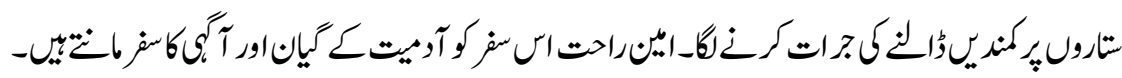

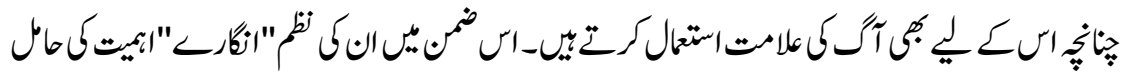

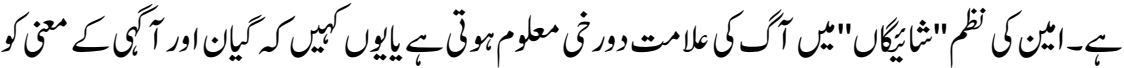




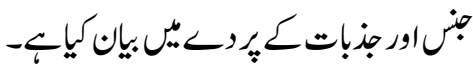

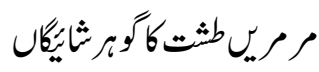

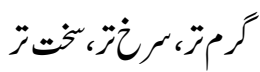

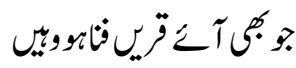

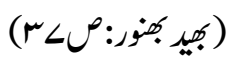

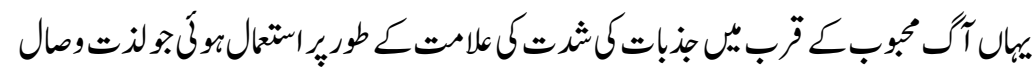

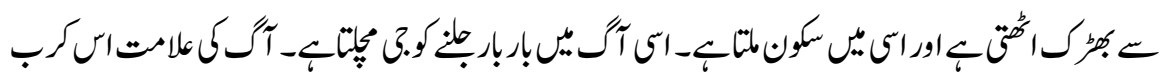

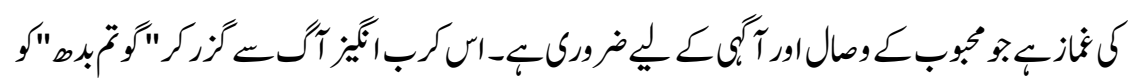

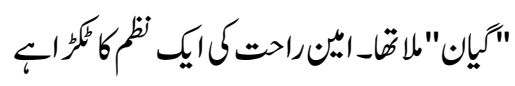

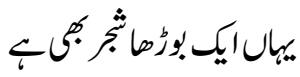

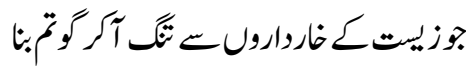

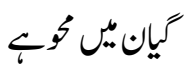

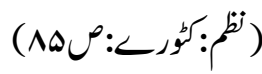

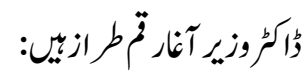

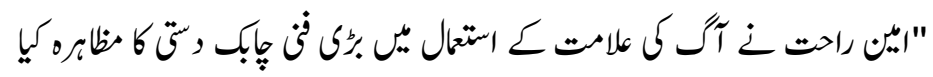

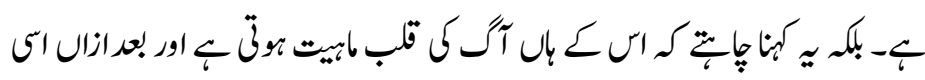

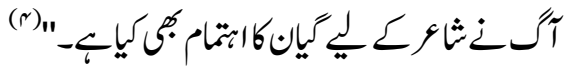

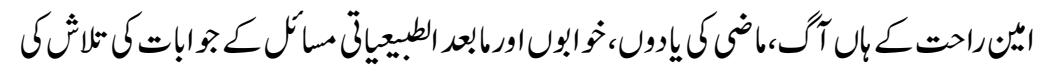

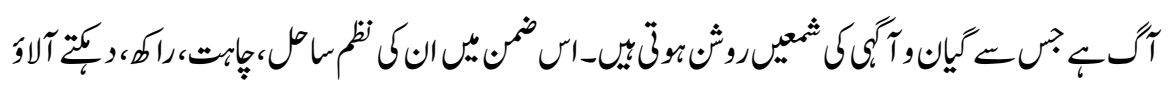

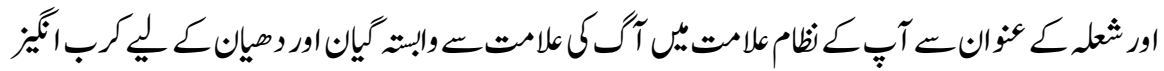

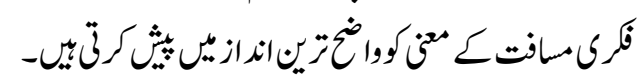

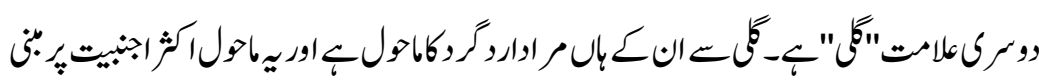

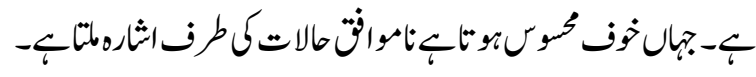




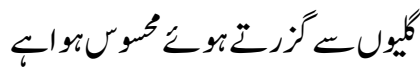

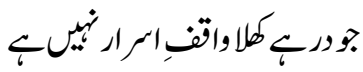

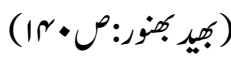

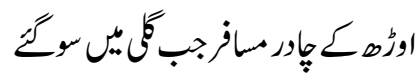

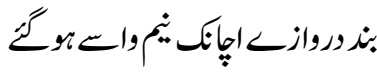

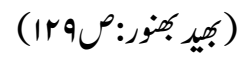

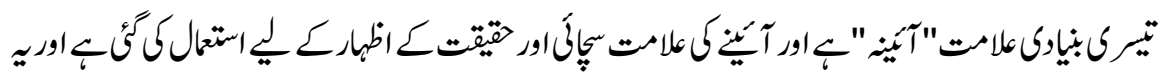

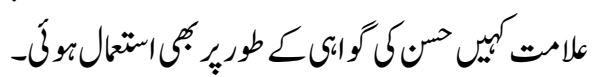

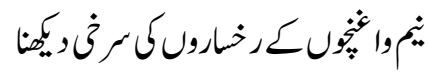

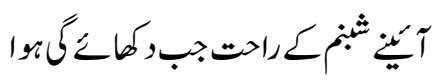

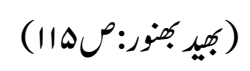

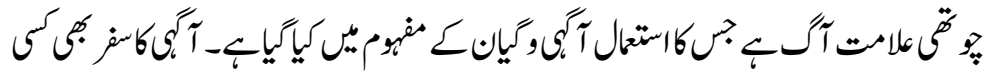

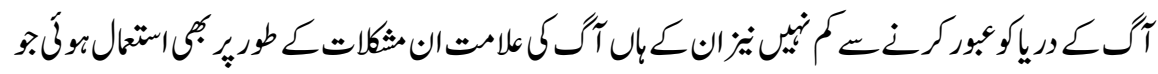

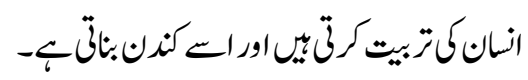

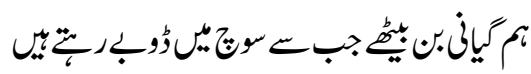

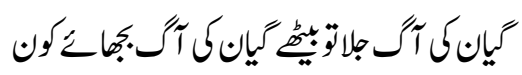

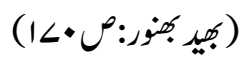

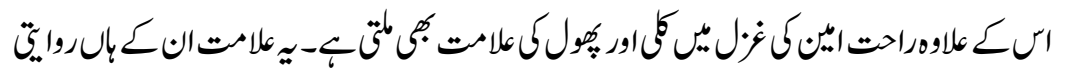

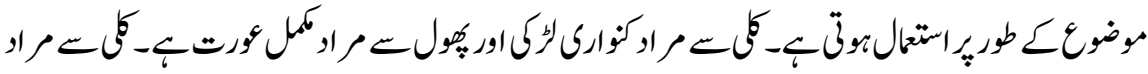

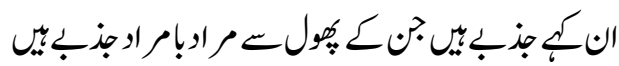

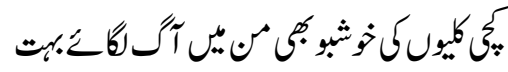

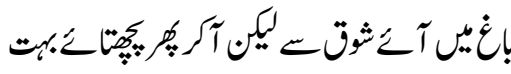

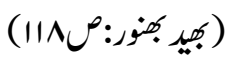


ISSN (Print): 2709-9636 | ISSN (Online): 2709-9644

Volume 2, Issue IV, (October to Decmber 2021)

اخزتيقيق مجلر

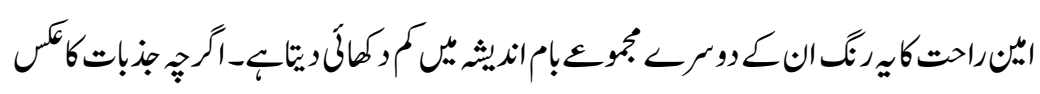

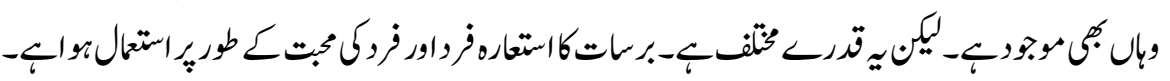

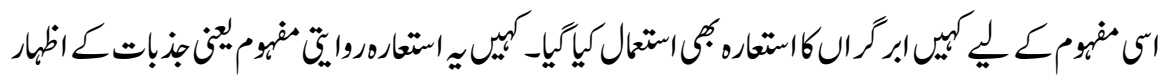

$$
\begin{aligned}
& \text { 每 }
\end{aligned}
$$

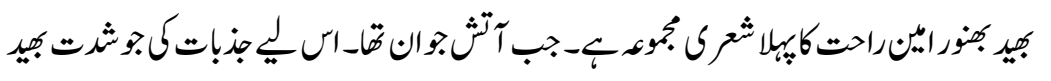

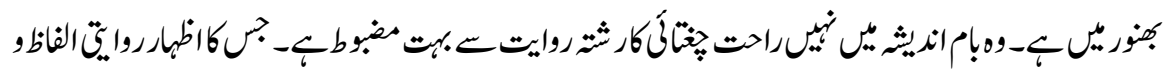

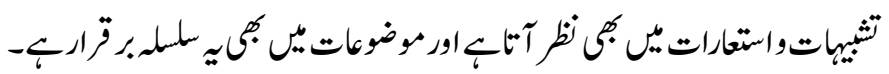

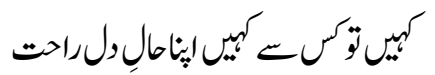

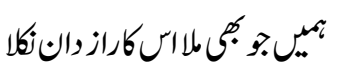

$$
\begin{aligned}
& \text { (بير جمنور:ص<ان (11) }
\end{aligned}
$$

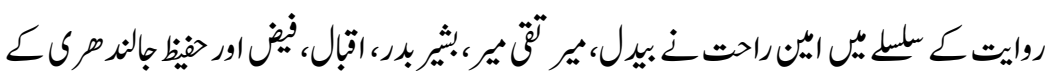

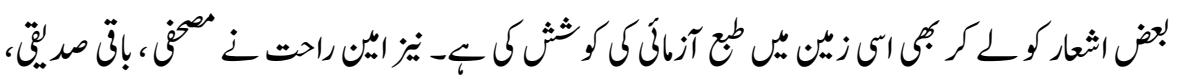

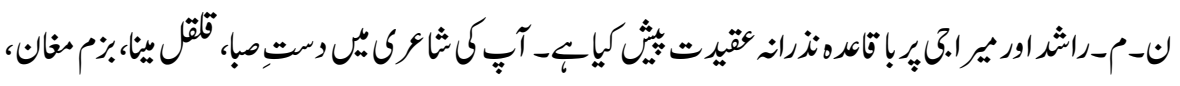

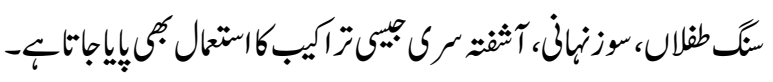
ا

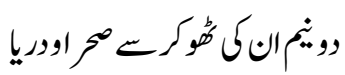

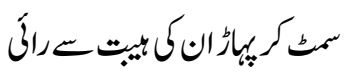

(iقال)

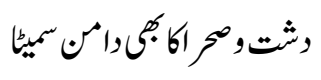

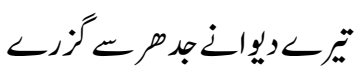

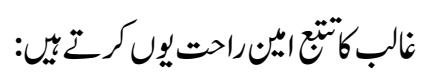

$r$ 


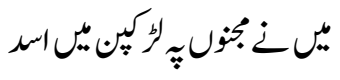

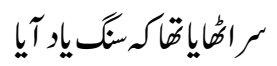

(ناب)

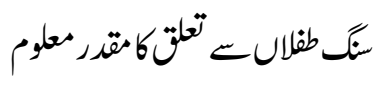

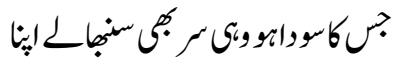

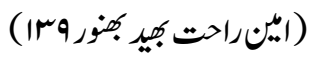

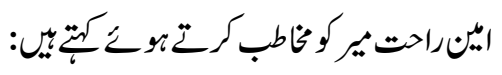

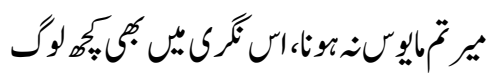

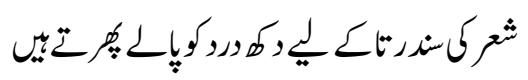

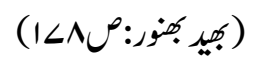

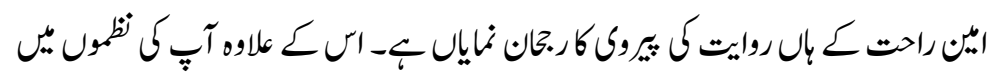

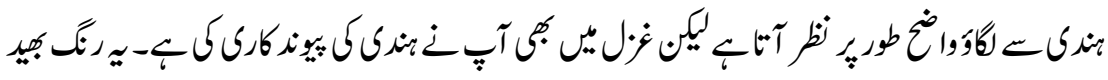

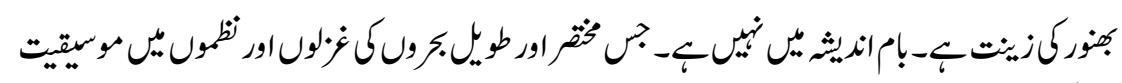

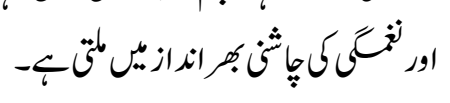

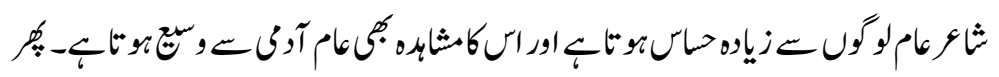

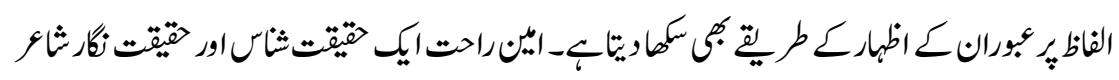

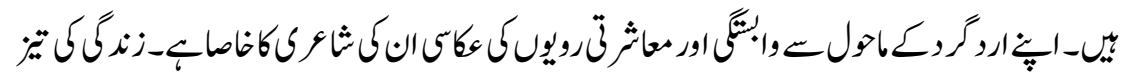

$$
\text { رنتركيروهيول كويابين: }
$$

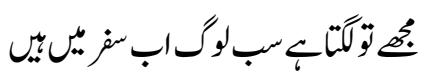

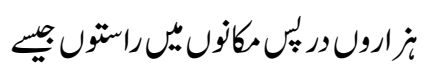

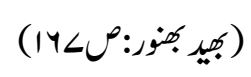




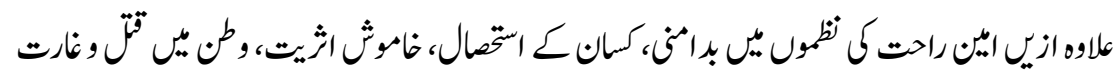

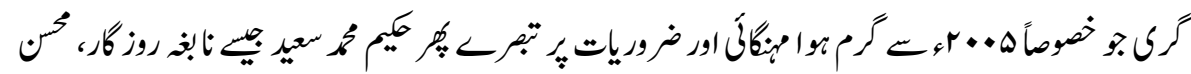

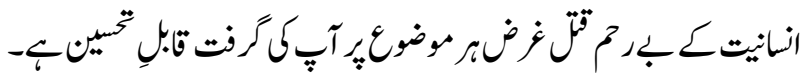

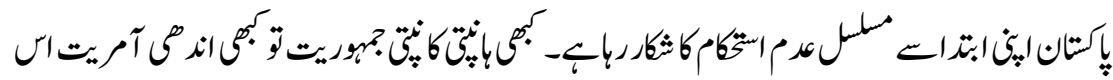

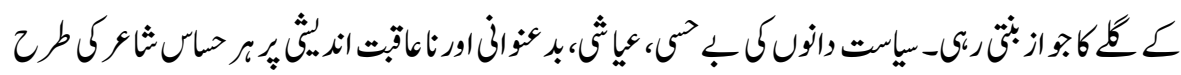

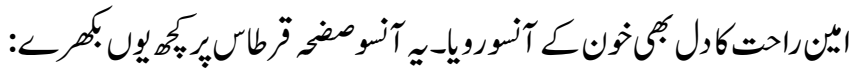

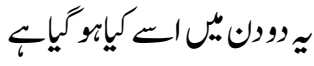

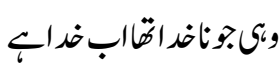

$$
\text { (بمي كمنور) }
$$

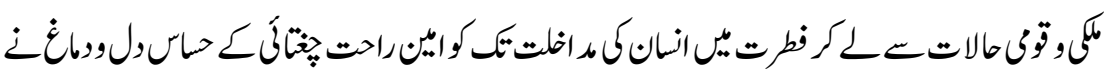

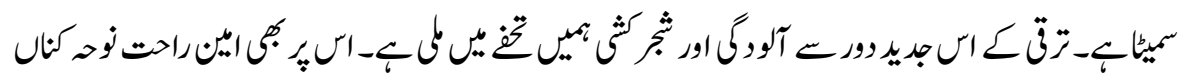

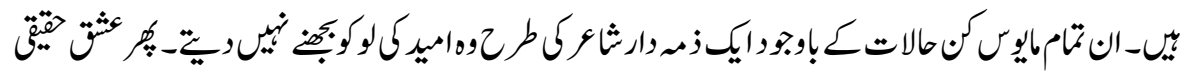

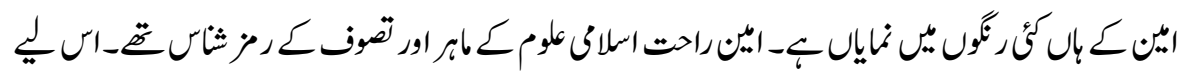

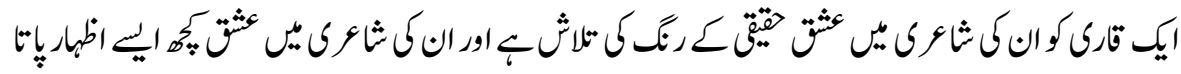

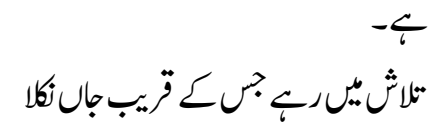

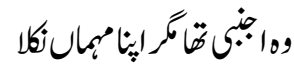

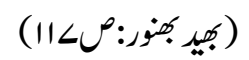

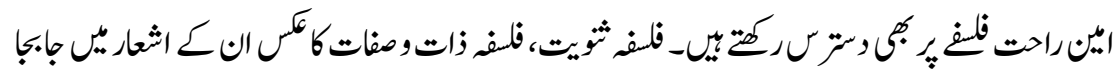

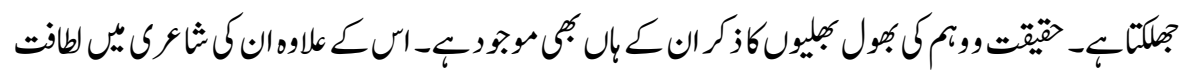

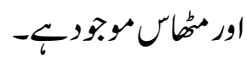

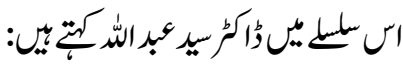




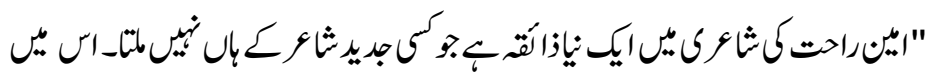

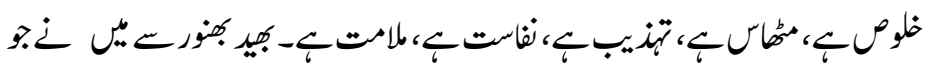

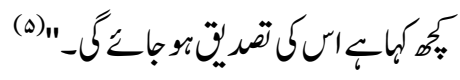

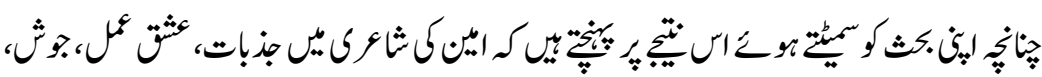

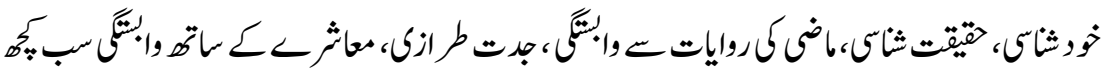

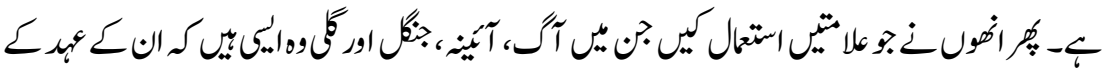

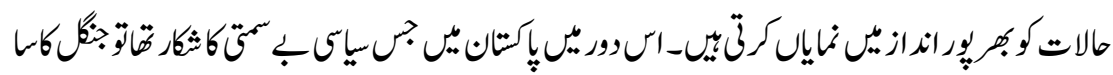

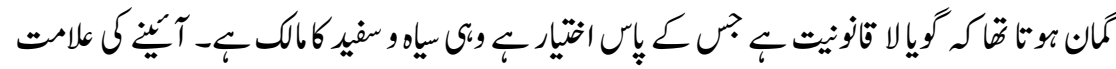

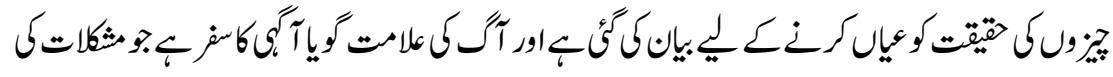

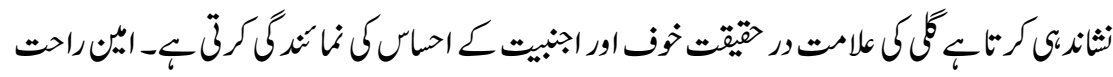

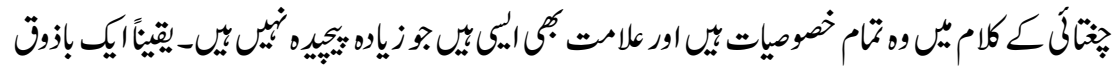

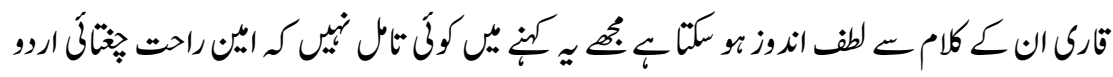

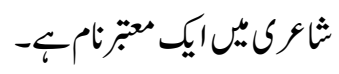

و توالدجات

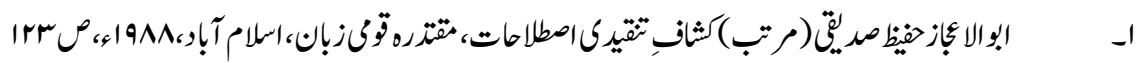

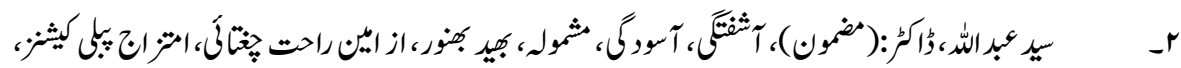

$$
\text { لانبور، }
$$

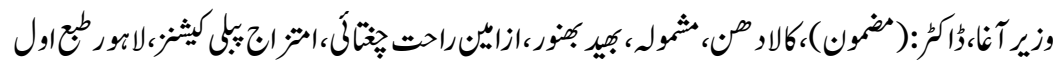

$$
1<0^{\infty}, 1914
$$

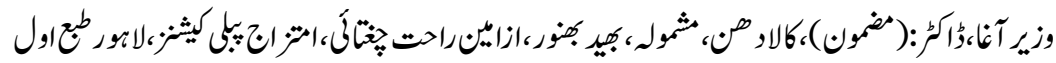

$$
\text { revecs9ar }
$$

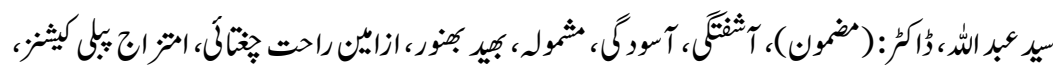

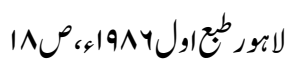

